\title{
Simulation about Warm Forming Deep Hole in Sheet
}

\author{
X.C. Xu*, Z.R. Chen, X.C. Ma and F. Guo \\ Harbin University of Science \& Technology, Harbin, Heilongjiang Province \\ 150080, P.R. China \\ *1120549159@qq.com
}

\begin{abstract}
The processing of forming deep hole in sheet is a kind of process using friction heat between drilling tool and workpiece to make workpiece in plastic deformation to machine hole. The process is a kind of green mechanical processing without chip. Studying green processing process in mechanical is becoming a development direction. In this paper, simulated analysis about the influence of processing parameters on the friction heat and the shape of forming hole, and researched on the temperature area of warm forming to machine hole, and then studied on quality of the hole in different temperature area in order to determine the appropriate warm extrusion temperature; Finally contrasted analysis the size of the hole of different location of test and simulation. The research results show that the simulation results agree well with the actual test results, and the warm extrusion is useful to form hole under the condition of a certain thickness.
\end{abstract}

Keywords: Simulation, Forming hole, Sheet, Warm forming, parameters

\section{Introduction}

The processing technology of machining hole whose deep is bigger than sheet thickness in sheet is a new processing method, which uses the friction heat between the drill tool and the workpiece to make the workpiece material under the drill tool happen plastic form, similar to the extrusion process[1,2] Currently, the related research literatures at home and abroad are not much, the main research contents mainly are for drill friction heat production model, the influence of process parameters on the drilling[3], the blade geometry design[4], cutting tool material[5] and workpiece material microstructure analysis of several aspects, such as forming area[6]. And these studies are all about hot forming, its processing temperature is above the recrystallization temperature of the sheet material. Because the material in higher temperature has higher plasticity and smaller deformation resistance, the hole is easy to take shape. Because sheet happens hot forming artifacts, some phenomenon is easy to happen, such as oxidation, decarburization, overheating and drilling tool bad thermal wear, then affect the performance of the workpiece. It is necessary to explore the forming under the temperature lower the recrystallization temperature, although the deformation resistance of workpiece material is a bit high, but the effect of strain hardening may be useful to workpiece performance and surface quality of hole.

Numerical simulation is a kind of effective methods to research sheet metal stamping and extrusion $[7,8]$. In this paper, based on simulation researching about the influence of processing parameters on the friction heat, the simulation analysis focused on forming hole under below its recrystallization temperature about the deformation resistance of materials during warm forming, analysis appropriate processing temperature of the warm extrusion processing and processing parameters. 


\section{Simulation Analysis of the Influence of Processing Parameters on the Friction Heat}

\subsection{Simulation Preparation}

In this paper, the drilling tool materials is YG6X cemented carbide, the workpiece is 20 steel whose thickness is $3 \mathrm{~mm}$. At the first, drew two objects geometric model in the UG, and then convert it to STL format into the finite element simulation software Deform, such as pretreatment and mesh work, as shown in Figure 1 and Figure 2.

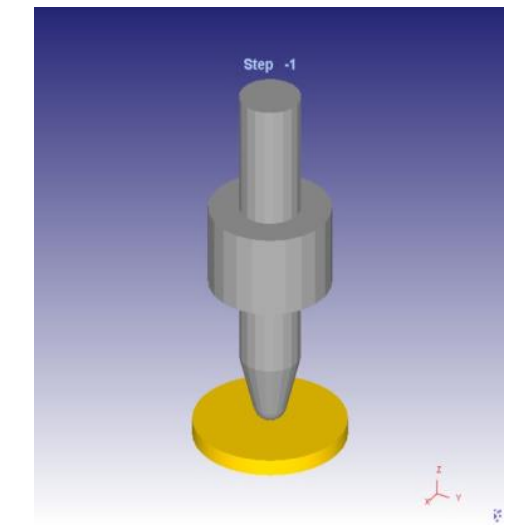

Figure 1. Geometric Model

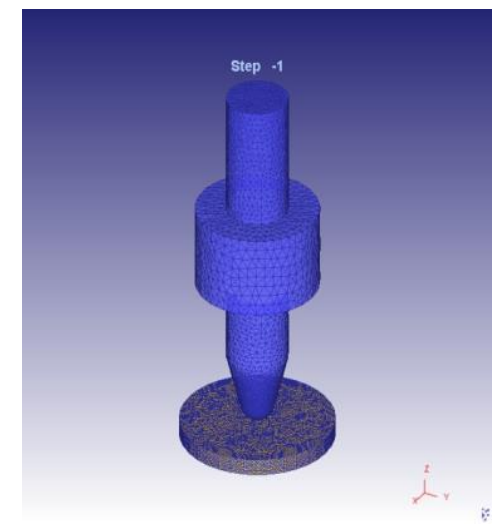

Figure 2. Meshing

\subsection{Influence of feeding speed}

Figure 3 is simulation temperature contours of DEFORM-3D with different axial feeding speed of drilling tool.

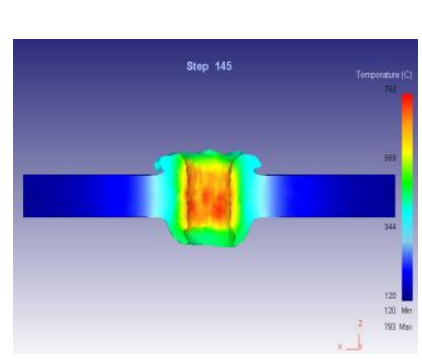

a) $f=0.5 \mathrm{~mm} / \mathrm{s}$

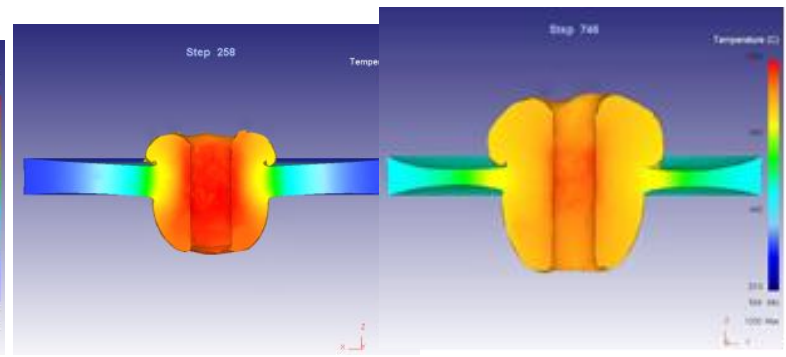

b) $f=1.5 \mathrm{~mm} / \mathrm{s}$

c) $f=2.5 \mathrm{~mm} / \mathrm{s}$

Figure 3. Layout of Temperature Field with Different Feed Speed

In the whole forming, the workpiece temperature of forming zone rose rapidly, and then leveled off first with the increased of drilling depth shown as in Figure 3.

The feed speed can make different deformation zone temperature. When under the condition of the same speed, feed speed of drilling tool is slow and the contact of time sheet is long, the friction heat is big, although the time of heat exchange between sheet heat and outside air is longer, but it is little compared to the frictional heat, so that higher temperature of deformation zone produced. And because the heat conduction effect time is long, temperature distribution in the workpiece is relatively average; contact time between the tool and workpiece decreases when the feed speed is quick, the temperature is reduced.

In addition, the hole wall thickness of bottom convex is different when the feed speed is different, the wall thickness of convex platform under the bottom of hole increased with 
feed speed. Because under the same speed, when the feed speed is bigger, in a part of the material to the reverse flow hole area, conical part of the drilling tool pushes convex platform under the form below. The simulation results show that a hole choose the appropriate feed speed to control the fluctuation of geometric convex scale according to the actual situation.

\subsection{Influence of Speed}

The influence of speed on the hole shape is shown in Figure 4.

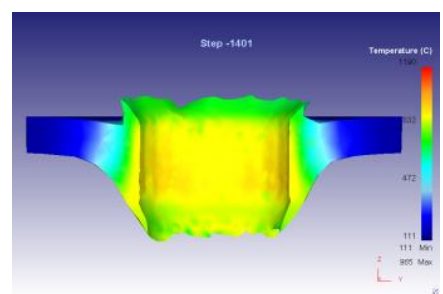

a) $n=1500 \mathrm{r} / \mathrm{min}$

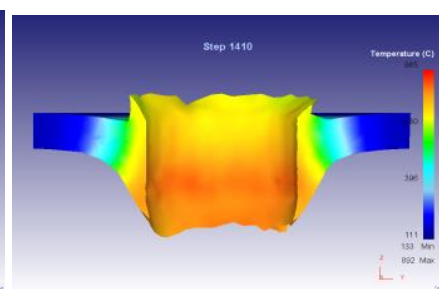

b) $n=2500 \mathrm{r} / \mathrm{min}$

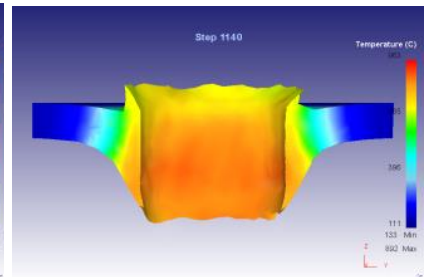

c) $n=3500 \mathrm{r} / \mathrm{min}$

Figure 4. Layout of Temperature Field with Different Speed Cases

The sheet deformation zone temperature also increases gradually with the increase of tool rotation speed when the feed rate is constant. The highest temperatures of deformation zone with the corresponding three kinds of drilling rate are $778^{\circ} \mathrm{C}, 1140^{\circ} \mathrm{C}$ and $1230^{\circ} \mathrm{C}$. The higher the temperature of hole area is, the greater depth of convex is, because high temperature makes to increase the metal plasticity.

\section{Study on the Temperature Range of Warm Extrusion Forming Hole}

The temperature range of Warm extrusion processing is usually considered to be during room temperature and the recrystallization temperature of materials. Classification of forging is divided into hot forging (forging temperature is above the recrystallization temperature of the metal), warm forging (forging temperature is below the recrystallization temperature of the metal) and cold forging (room temperature).The recrystallization temperature of the steel is about $463^{\circ} \mathrm{C}$ according to deformation temperature, but generally $800^{\circ} \mathrm{C}$ is used as a dividing boundaries, forging is to be seen as hot forging when forging temperature is more than $800^{\circ} \mathrm{C}$; Between $300 \sim 800^{\circ} \mathrm{C}$, forging is called warm forging or half hot forging. In this paper, the processing method is similar to extrusion processing, so this paper chosen reference temperature range of the warm extrusion processing temperature according to forging temperature. This is a relatively large temperature range. In this paper, machining deep hole in sheet happens in short time, so it is necessary to segment carefully deformation temperature range by simulation analysis in order to determine the appropriate process parameters.

In this paper, workpiece material is 20 steel, the relation curve between deformation resistance and temperature of 20 steel is shown as Figure 5. 


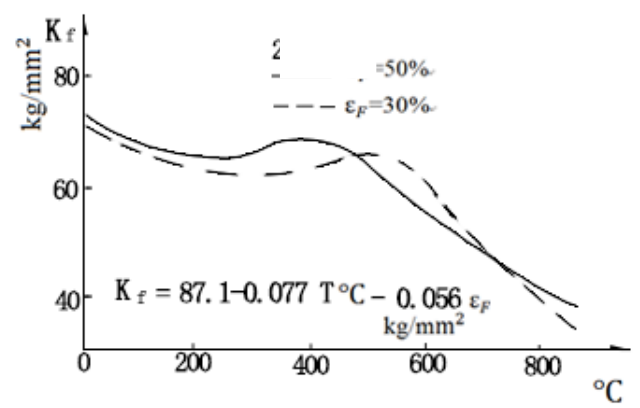

Figure 5. Relation between Deformation Resistance and Temperature of 20 Steel

AS shown in Figure 5, if the deformation degree of 20 steel is constant, the deformation resistance decreases when temperature increases during $0 \sim 300^{\circ} \mathrm{C}$; In $300 \sim$ $450^{\circ} \mathrm{C}$, the deformation resistance begins to rise, and after $450^{\circ} \mathrm{C}$, the deformation resistance restores increasing trend with the temperature lowering. This reason is that 20 steel often happens blue brittle at temperature range between $300 \sim 450^{\circ} \mathrm{C}$. The blue brittle causes that material plastic decrease and material brittleness increases.

On the other hand, Carbon steel is easy to oxidize phenomenon in thermoplastic forming, and the oxidation phenomenon may cause matrix corrosion of processed materials and surface decarburization, then affecting workpiece performance. The relation between oxidation and heating temperature of 20 steel is shown in Figure 6.

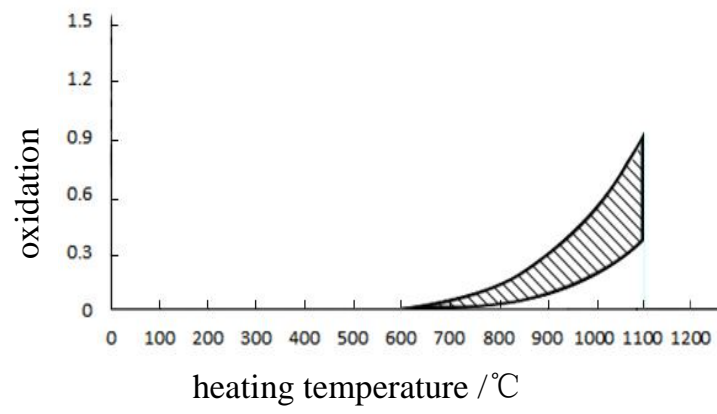

Figure 6. Oxidation Situation of 20 Steel in Heating

AS shown in Figure 6, oxidation degree of 20 steel increases quickly after $600^{\circ} \mathrm{C}$ with the temperature increasing, and peaks in $1100^{\circ} \mathrm{C}$. This paper studies on the warm extrusion forming, the temperature range is from 300 to $800^{\circ} \mathrm{C}$, so before the $600^{\circ} \mathrm{C}$, the paper needn't to consider the oxidation problem of materials. $600^{\circ} \mathrm{C}$ is as a critical point to research the warm extrusion temperature range.

According to above analysis, we identified the warm extrusion temperature range is from 300 to $800^{\circ} \mathrm{C}$, depending on the materials of the deformation resistance and blue brittle temperature, ruled out the unreasonable temperature range forming hole of 300$450^{\circ} \mathrm{C}$. According to the oxidation of steel during hot working situation again, and the rest of the temperature range is divided into two intervals for forming simulation.

\section{Simulation Analysis for Warm Extrusion}

Raising the temperature of processed sheet is divided into two parts: the first is that the drilling tool with a initial contact, high-speed rotating in certain axial force and the very small feed speed to the sheet, temperature rises by the friction between the drill tool and 
workpiece surface until the temperature of the warm extrusion processing; Then continue to exert larger axial force and high feed speed to form hole.

\subsection{Study on Forming Hole in $300-600{ }^{\circ} \mathrm{C}$}

Using of DEFORM 3 d simulation software, first of all, for simulating heating up stage by friction, set the analog control mode, the types of simulation, the import file geometry and mesh, then set the movement parameters and material handling work. The simulation temperature nephogram of warming phase is shown as in Figure 7.

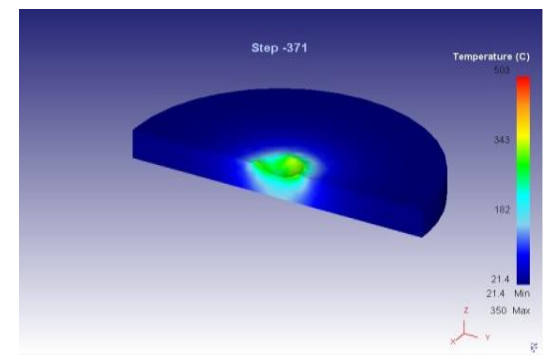

a)

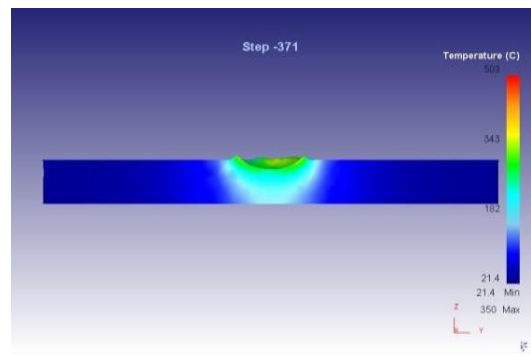

b)

Figure 7. The Simulation Temperature Nephogram in Warming Phase

When the temperature of hole forming zone reaches the required temperature range, the simulation for forming hole begins the second step, the other parameters are same as first stage, but changes the feeding speed.

Pretreatment to save the data for the DB file, after the completion of exit before treatment, start to run. The simulation results can be observed in the post-treatment after the calculation. The simulation results within the temperature range of $400 \sim 600^{\circ} \mathrm{C}$ are shown in Figure 8.
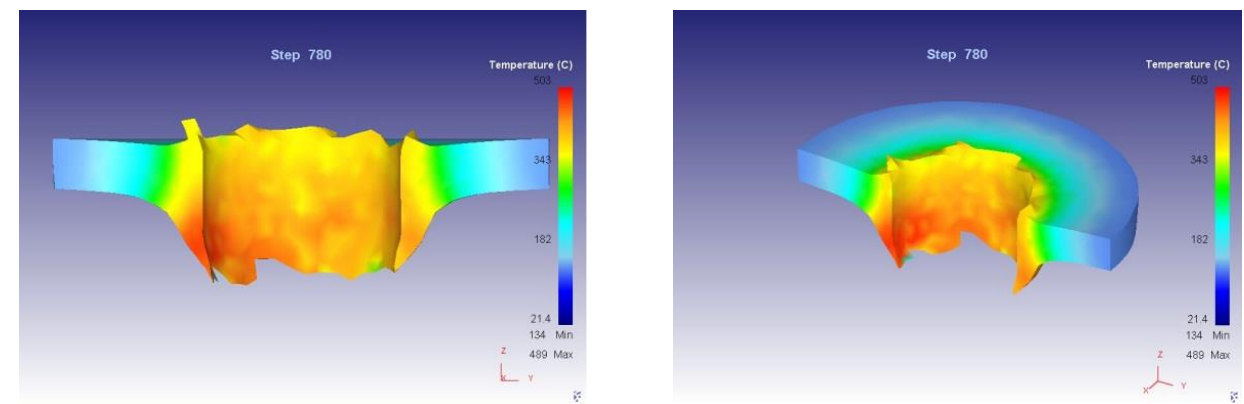

Figure 8. Forming Hole within the Temperature Range of $400-600^{\circ} \mathrm{C}$

From the simulation diagram in Figure 8, we can know that the temperature is lower, because of the low plastic of sheet metal and poor malleability, formed hole shape is not very good, and the ends of the hole is not very neat. The deep of hole is only about two times of the sheet thickness. On the whole, the hole morphology is not enough good.

Forming hole within the temperature range of $300 \sim 600^{\circ} \mathrm{C}$, the axial force of $\mathrm{Fz}$ is shown in Figure 9. Axial force of the drilling tool is bigger, and fluctuates significantly. At the hole forming temperature range of $300 \sim 600^{\circ} \mathrm{C}$, the temperature at forming hole area is low, and sheet deformation resistance is big, so forming hole need larger axial force. 


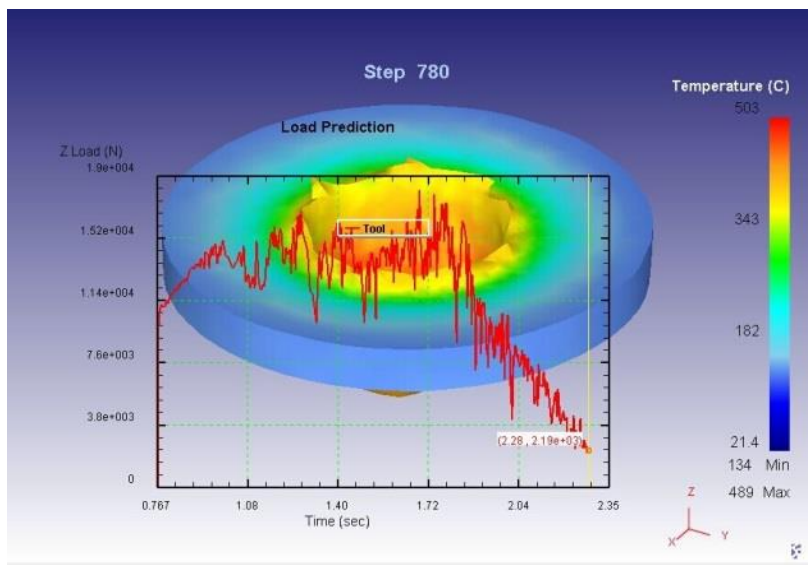

Figure 9. Axial Load Simulation Map

\subsection{Study on Forming Hole in $600-800{ }^{\circ} \mathrm{C}$}

The simulation parameters are unchanged, forming uniform temperature is between $600 \sim 800^{\circ} \mathrm{C}$. The simulation result of heating is shown in Figure 10.

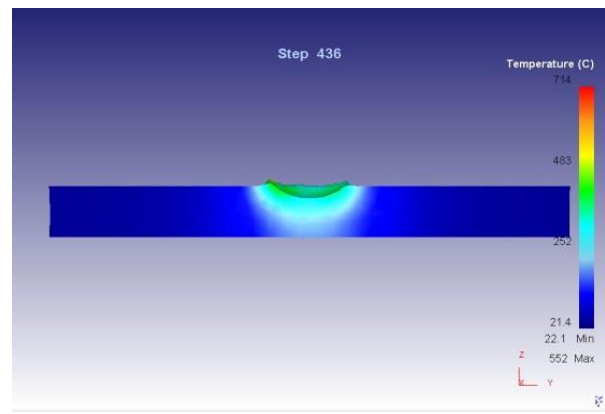

a)

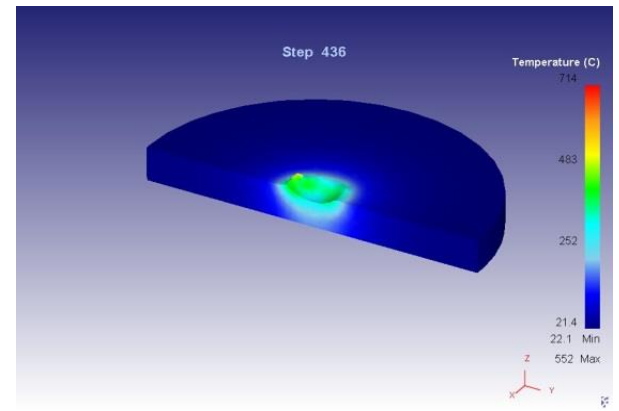

b)

Figure 10. Simulation Map of Heating in Forming Hole

The simulation results observed in the post-treatment after the calculation are shown in Figure 11. Within the temperature range from 600 to $800^{\circ} \mathrm{C}$, the hole forming simulation diagram showed that the hole surface is smooth, and the thickness of end of hole is homogeneous and continuous. The hole depth is about 2.5 times as sheet thickness. The hole morphology formed in $600-800^{\circ} \mathrm{C}$ is more perfect than above hole morphology formed in $300-600^{\circ} \mathrm{C}$.

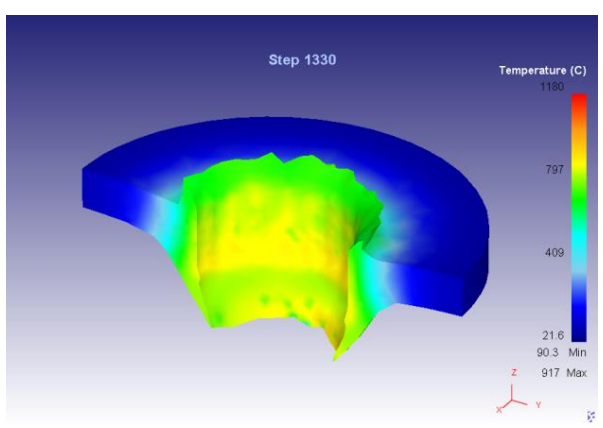

a)

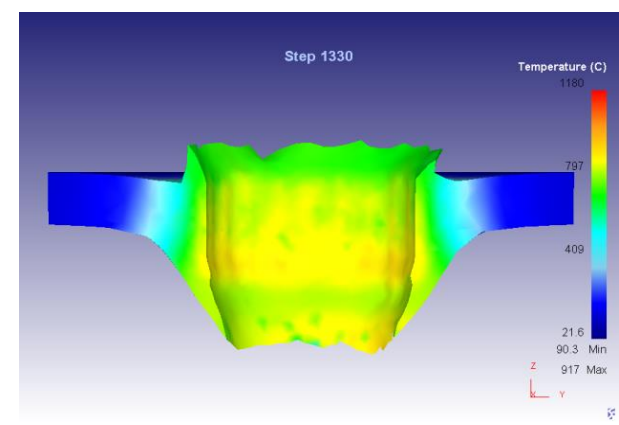

b)

Figure 11. Simulation Map of Forming Hole in $600-800^{\circ} \mathrm{C}$ 
The relationship between axial load and time is shown in Figure 12 when forming during $600-800^{\circ} \mathrm{C}$ by simulation.

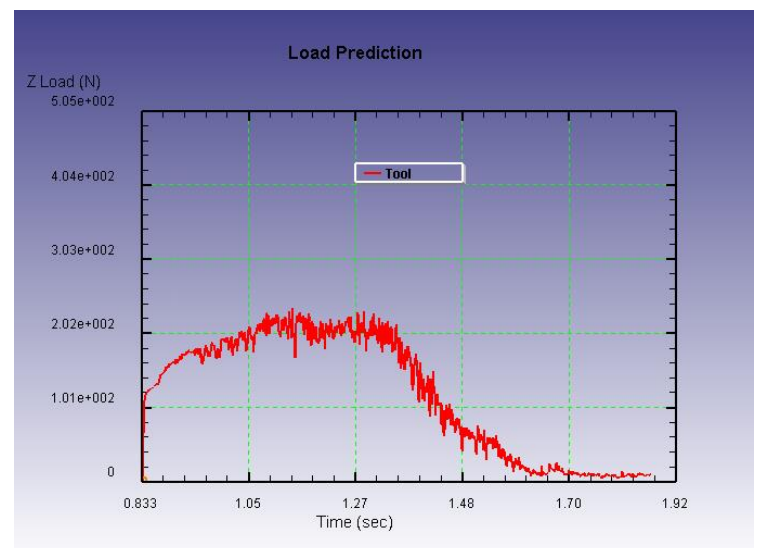

Figure 12. Axial Load into the Hole

In Figure 12, there are three axial force stages in whole forming hole: extrusion stage, at this stage, as the tool feeds down, axial force increased gradually; the forming is into the extruding bulging combination stage after starting bulge, at this stage, the axial force slightly decrease, then increase. The forming is into bearizing stage after bursting, this stage begins to gradually reduce the axial force. When the cone part fully penetrates the sheet, the axial force is to a minimum that is so small that can be neglected.

\section{Test Analysis}

In order to verify the simulation results, test to form deep hole in sheet, material: 20 steel; Thickness: $3 \mathrm{~mm}$; feed speed: $\mathrm{f}=5 \mathrm{~mm} / \mathrm{s}$; speed of drilling tool: $\mathrm{n}=2500 \mathrm{r} / \mathrm{min}$. Figure 13 is a diagram of formed hole.

The forming temperature in hole area is about $700^{\circ} \mathrm{C}$, and measured three groups numerical data at different position of the hole shown in Figure 14, then compared the simulation results with test data shown as Table 1 .

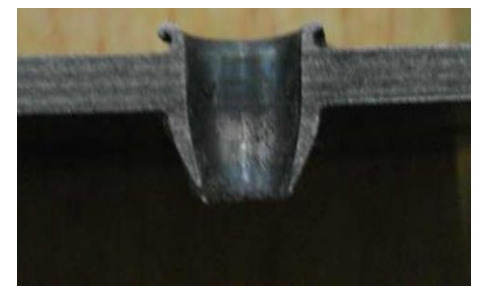

Figure 13. Hole by Test

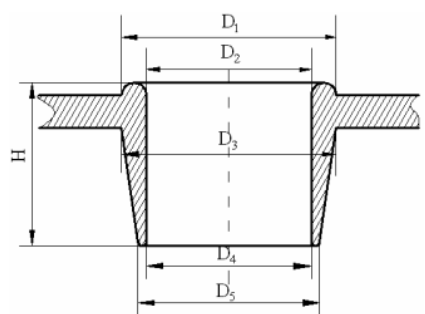

Figure 14. Measured Position

Table 1. Hole Parameters Of Drill Tool Of Diameter $8 \mathrm{~mm}$ (Mm)

\begin{tabular}{c|c|c|c|c|c|c|c}
\hline \multicolumn{2}{c|}{$\Phi 8$} & $D_{1}$ & $D_{2}$ & $D_{3}$ & $D_{4}$ & $D_{5}$ & $H$ \\
\hline \multirow{3}{*}{ test } & 1 & 10.44 & 8.06 & 9.94 & 8.06 & 8.34 & 11.92 \\
\cline { 2 - 8 } & 2 & 10.42 & 8.04 & 9.94 & 8.08 & 8.74 & 11.06 \\
\cline { 2 - 8 } & 3 & 10.44 & 8.04 & 9.93 & 8.06 & 8.52 & 11.08 \\
\hline \multicolumn{2}{c}{ simulation } & 9.48 & 8.34 & 9.71 & 8.02 & 8.52 & 9.01 \\
\hline
\end{tabular}


The results of observation and measurement can show that along the axis of the hole wall, hole size is not the same everywhere, from the top to bottom, the aperture size becomes small, this is because the process sheet is heated, hole forming zone temperature is higher, after processing, the workpiece cools down, shrinkage of different position is different.

The simulation results agree with test results reasonably. The main reason of error is because of the simplification and assumption of the simulation model; simulation process and test process are not the same completely. It needs further in-depth study in order to improve the simulation accuracy.

\section{Conclusions}

Base on researching on warm extrusion processing and deformation resistance, the analysis of the blue brittle, oxidation, and so on, the suitable temperature range for warm extrusion forming is during $600-800^{\circ} \mathrm{C}$; The simulation results agree with test results reasonably by comparing with the simulation results and test results, which shows suitable processing parameters may be selected by simulation for forming hole in sheet by friction heat.

\section{References}

[1] S.F. Miller, J. Tao and A.J. Shih, "International Journal of Machine Tools \& Manufacture", vol. 46, (2006).

[2] Y.H. Wang, "Machine tool \& hydraulics", vol. 3, no. 36, (2008), (In Chinese).

[3] W.L. Ku, T.S. Sheu, H.M. Chow, S.M. Lee, L.D. Yang, Y.C. Lin and W.S. Zhao, Proceeding of 16th international symposium on electromachining, April 19-23 (2010), Shanghai, China

[4] Y. Zhang, Journal of Hefei University of Technology, vol. 6, no. 25, (2002).

[5] S.F. Miller and A.J. Shih, Journal of Manufacturing Science and Engineering, vol. 3, pp. 129, (2007).

[6] X. Xu and Y. He, Applied Mechanics and Materials, vols. 37-38, (2010).

[7] J. Dai, D. Li and F. Li, "Journal of Harbin University of Science and Technology", vol. 3, no. 18, (2013), (In Chinese).

[8] X. Liu, B. Liu, X. Chen, Q. Pan and Y. Zhang, Journal of Harbin University of Science and Technology, vol. 1, no. 20, (2015), (In Chinese). 